Motrivivência $\quad$ v. 27, n. 46, p. 171-184, dezembro/2015

\title{
REFLEXÕES SOBRE O TRABALHO DO PSICÓLOGO DO ESPORTE EM UMA ACADEMIA DE GINÁSTICA
}

\author{
Livia Gomes Viana-Meireles' \\ Zulmira Aurea Cruz Bomfim² \\ Erick Francisco Quintas Conde ${ }^{3}$ \\ Angela Donato Oliva ${ }^{4}$
}

\section{RESUMO}

O presente estudo buscou desenvolver uma reflexão sobre a prática do psicólogo do esporte dentro de uma academia de ginástica, a partir do relato de experiência de estágio em psicologia. Refletimos sobre o papel desse profissional no referido espaço, buscando construir ações afinadas com o campo de psicologia do esporte. O trabalho abarcou intervenções junto aos alunos e professores. Ao fim, a experiência de estágio evidenciou a possibilidade de atuação do psicólogo do esporte nas academias de ginástica, apontando para ações de promoção de saúde e apoio ao trabalho da equipe, contribuindo, assim, para o desenvolvimento de ações no campo da psicologia do esporte.

Palavras-chave: Psicologia; Academias de Ginástica; Adesão à Atividade Física

1 Doutora em Psicologia Social. UERJ, Rio de Janeiro/Rio de Janeiro, Brasil. E-mail: liviagviana@gmail.com

2 Pós-doutora em Analisis y Intervención Social y Ambi. Professora do curso de graduação e mestrado em Psicologia da UFC, Fortaleza/Ceará, Brasil. E-mail: zulaurea@gmail.com

3 Doutor em Neurociências. Professor Adjunto no Departamento de Psicologia da UFPE, Recife/Pernambuco, Brasil. E-mail: psicoerick@yahoo.com.br

4 Doutora em Psicologia Escolar e do Desenvolvimento Humano. Professora da graduação e do programa de pós-graduação em Psicologia Social da UERJ, Rio de Janeiro/Rio de Janeiro, Brasil.

E-mail: angeladonatoliva@gmail.com 


\section{INTRODUÇÃO}

A inserção do psicólogo no meio esportivo amplia os horizontes da Psicologia enquanto ciência e profissão, com consequências diretas na pesquisa e na atuação de profissionais em um campo em desenvolvimento (RUBIO, 1999). A Psicologia do esporte, portanto, tem caráter científico, na medida em que estuda os comportamentos das pessoas em contextos esportivos (WEINBERG; GOULD, 2001), e pode ser considerada uma das áreas emergentes da Psicologia no Brasil.

Rubio (2007), Carvalho e Sampaio (1997) destacam que essa Psicologia, com todas as suas especificidades, se desenvolveu em meio a diversas abordagens psicológicas, fazendo uso de diferentes métodos e instrumentos de avaliação e intervenção. Em 2000, o Conselho Federal de Psicologia, a partir da resolução 014/00, passou a considerar a Psicologia do esporte como especialidade da Psicologia, regulamentando o exercício profissional e a formação dos psicólogos (RUBIO, 2007), incluindo-a como uma possível área de estágio na formação dos cursos de graduação em Psicologia. Apesar do aumento do interesse por parte dos estudantes e da crescente procura de psicólogos do esporte, os cursos de Psicologia, em sua maioria, não oferecem a disciplina de psicologia do esporte, e soma-se a isso a pouca oferta de cursos de especialização (SILVA et al, 2014).

A produção científica dessa área tem crescido, nos últimos tempos, e tem oferecido material para o psicólogo atuar em diferentes ambientes esportivos, agregando conhecimentos dos vários campos da Psicologia, além de ser influenciada por diferentes paradigmas e correntes teóricas referentes à metodologia (RUBIO, 2007). Pode-se, no trabalho do psicólogo do esporte, utilizar métodos como a observação, a análise e intervenção cognitiva e comportamental, abordagens em Psicologia social, Psicologia do desenvolvimento, Psicologia clínica e Avaliação psicológica, todas inseridas nas especificidades do contexto do esporte e do exercício (RUBIO, 2002). Constatou-se que a participação em exercícios tem contribuído para o desenvolvimento psicológico e bem-estar dos indivíduos (MACHADO et al., 2007) o que fortalece a necessidade de pensar sobre os fatores psicológicos envolvidos na prática esportiva.

O psicólogo que se dedica à área do esporte pode atuar em diferentes contextos, entre eles o alto rendimento, a iniciação esportiva, esportes de competição, de reabilitação, escolar ou de lazer, incluindo espaços como academias, parques ou clubes. Em qualquer um desses espaços o olhar do psicólogo pode auxiliar na necessidade de conhecer o psiquismo de atletas e de praticantes de atividade física em geral, contribuindo para integração entre mente e corpo (EPIPHANIO, 1999).

As academias de ginástica são um local onde a presença do psicólogo do esporte pode auxiliar na adequação e acompanhamento dos praticantes de exercício físico (MONTEIRO, 2004). A busca de um estilo de vida saudável que inclua a prática de atividade física periódica é o recomendado para obtenção de uma boa qualidade de vida, pois a modernidade modificou muitos hábitos alimentares e contribuiu com o sedentarismo, o que pode ser relacionado à obesidade e doenças associadas a esse quadro, como o aparecimento de estresse e estafa (FLEGAL et al., 2010). 
Destarte, o objetivo deste artigo é desenvolver uma reflexão sobre a prática do psicólogo do esporte dentro de uma academia de ginástica a partir do relato de estágio. Para tanto, na primeira parte é apresentada a revisão de literatura que auxiliou no embasamento das ações do estágio, seguida do delineamento das ações e das atividades realizadas, entre elas a aplicação de um questionário em forma de pesquisa de satisfação com os alunos, treinamento com professores e avaliação do ambiente, as quais propiciaram reflexões sobre atuação multidisciplinar do psicólogo nesse contexto.

\section{Contextualizando o ambiente esportivo: a academia de ginástica}

O surgimento das academias vem com a proposta de oferecer à população urbana a possibilidade da prática regular de atividade física. Na década de 1960, houve uma proliferação das academias nas principais cidades brasileiras, atingindo aquelas pessoas que queriam fazer atividade física fora dos clubes (TAHARA; SCHUAWARTZ; SILVA, 2003). As academias de ginástica surgem, pois, como espaços de lazer, de encontro, de alegria, de cultura corporal e prazer pela prática da atividade física, proporcionando bem-estar e autonomia do indivíduo (COELHO FILHO; VOTRE, 2010; TOLEDO; PIRES, 2008). É um espaço em que as pessoas podem buscar uma conscientização quanto à saúde e o cuidado com o estilo de vida pessoal, com a alimentação, o sono, etc. (COELHO FILHO; VOTRE, 2010).

Para Hansen e Vaz (2004), as academias são entendidas como espaço de transformação do corpo, junto a outros espaços urbanos que propiciam o cuidado com a beleza e bem-estar, tais como salões de beleza, spas e lojas de tatuagem. Entretanto, também foram invadidas por uma competitividade que antes só existia nas modalidades esportivas de embate. Sendo assim, na academia existe uma organização que vai desde os aparelhos para musculação, divididos por grupos musculares, até uma classificação de atividades que despertam mais interesses dos homens e das mulheres: musculação mais pesada para eles e aulas em grupo para elas (HANSEN; VAZ, 2004). Entende-se, portanto, que é local de culto ao corpo, onde a obsessão pela boa forma pode gerar riscos à saúde física e psíquica. Existem pessoas, por exemplo, que levam o treinamento na academia tão a sério quanto os atletas profissionais em outras modalidades, envolvendo-se até em competições.

De acordo com Theodoro, Ricalde e Amaro (2009), o início de um programa de atividade física, antes de gerar riscos, tem como um dos principais motivos a insatisfação com o próprio corpo ou com a imagem que se tem dele. No entanto, são diversos os motivos que levam as pessoas às academias, seja a preocupação com a estética corporal, numa busca por um corpo ideal, ou o reconhecimento mesmo da importância da atividade física para saúde e bem-estar, tão raros nos dias atuais (ANTUNES, 2003). Para Debord (1994), o corpo belo serve à sociedade da aparência na sociedade do espetáculo. Na "era da sociedade do espetáculo e do consumo" (BAUDRILLARD, 1995), o corpo ganha lugar de "mediador da felicidade, instrumento e passaporte de bem-estar" (SEVERIANO; REGO; MONTEFUSCO, 2010) exigindo que as pessoas busquem incessantemente esse ideal. Posto isso, a divulgação na mídia de um estilo de vida saudável e do ideal de corpo bonito contribui para o aumento do 
número de pessoas que buscam um espaço para modelar seu corpo de acordo com a atual estética exigida socialmente (THEODORO; RICALDE; AMARO, 2009).

Muitos fatores são apontados como motivos para as pessoas buscarem as academias, tais como divertimento, sentir-se bem, controle de peso, melhora da flexibilidade, redução dos níveis de estresse, risco reduzido de doenças cardiovasculares, redução do estresse e depressão, satisfação, construção da autoestima, socialização, entre outros (TAHARA; SCHWARTZ; SILVA, 2003). Ainda assim, a rotatividade é uma característica que acompanha o espaço das academias de ginástica, ou seja, muitas vezes as pessoas não se mantêm por um longo período se exercitando (PERES, 2007). Pesquisas revelam que o tempo disponível é o fator mais citado como dificuldade para se manter na prática regular de atividade física (RUBIO, 2002). Weinberg e Gould (2001) citam alguns fatores que, de uma forma geral, contribuem para que as pessoas se exercitem ou deixem de se exercitar: sexo e classe social, variáveis cognitivas e variáveis comportamentais. O ambiente social, o ambiente físico e as características da atividade física também podem influenciar na manutenção do indivíduo na prática regular e saudável de atividade física. Além desses fatores, os autores ainda apontam a falta de tempo, a falta de energia e a falta de motivação como motivos para as pessoas não se engajarem de forma contínua em uma atividade física.

O estágio em psicologia do esporte: possibilidades de atuação do psicólogo nas academias de ginástica

A primeira reflexão é quanto à formação generalista do psicólogo, que é treinado para aperfeiçoar seu olhar sobre as relações sociais em qualquer contexto. Os cursos de graduação em Psicologia ensinam a atuação desde as áreas mais tradicionais, como a clínica, saúde organizacional, escolar e de avaliação, como também as áreas ditas emergentes social-comunitária, jurídica, desportiva e outras (LISBOA; BARBOSA, 2009). O psicólogo, independentemente da área de atuação, aperfeiçoa seu olhar aos aspectos psicológicos envolvidos na realidade. Como a formação nos cursos de graduação de Psicologia em algumas áreas emergentes ainda é deficiente (LISBOA; BARBOSA, 2009), o psicólogo que tem intenção de atuar nessas áreas pode fazer uso de conhecimentos advindos da psicologia organizacional, do trabalho e da clínica, visto que na maioria dos currículos de psicologia não existe a disciplina específica de psicologia do esporte ou ela é ofertada como opcional (SILVA et al, 2014).

A Psicologia do Esporte, como já salientado anteriormente, recebe influência de conceitos e técnicas de outros campos da Psicologia, como a Psicologia Clínica, Psicologia Social, Psicologia do Desenvolvimento e Psicometria (SILVA et al, 2014). Essa acaba sendo a maneira de alguns estudantes, desde a graduação interessados por essa área, enveredarem nesse tema. $\mathrm{O}$ resultado é que acabam buscando estágios em ambientes esportivos sob a supervisão de professores de outras áreas de atuação, usando, por exemplo, estratégias como pesquisas de clima, recrutamento e seleção, treinamento e aperfeiçoamento de pessoal, advindas da Psicologia organizacional e do trabalho (SPECTOR, 2010). Da psicologia clínica pode-se trabalhar com a escuta e as avaliações psicológicas aplicadas ao contexto esportivo, além de utilizar de 
técnicas cognitivo-comportamentais, tais como o monitoramento de atividades para identificar um melhor horário para inserir a atividade física, reestruturação cognitiva e etc (MARTIN, 2001).

Como se pode ver, a literatura da área de Psicologia do esporte pode referendar inúmeras atuações, como o trabalho com metas, gerenciamento do tempo e motivação (MARTIN, 2001), no entanto, qualquer atuação deve ser contextualizada e, mesmo se tratando de um ambiente com características comuns, as diferentes academias que existem são lugares únicos e singulares, demandando tempo para conhecê-las antes de iniciar a atuação.

Para o psicólogo do esporte que atue nas academias de ginástica é importante que ele tente adequar sua ação à realidade de cada academia, levando em consideração as características acima citadas. A partir de uma pesquisa com os alunos da academia, o psicólogo pode tentar compreender o que motiva os alunos e quais as estratégias que podem ser usadas para proporcionar uma maior aderência à prática de atividade física nas academias de ginástica e musculação. O olhar do psicólogo também pode atuar diretamente com a equipe de professores da academia, pois a manutenção em programas de exercícios físicos é influenciada pelos professores e instrutores, sendo importante a atenção que os mesmos dão às suas aulas e aos praticantes de atividade física (PERES, 2007). Para Antunes (2003), as academias de ginástica devem ser um espaço democrático e acessível a todos e os professores de educação física devem estar preparados para atender qualquer perfil de aluno.

Em pesquisa realizada com professores de educação física que trabalham em academias, percebeu-se que, quando ques- tionados sobre sua formação acadêmica, eles tendiam a supervalorizar disciplinas biológicas e técnicas em detrimento das socioculturais, filosóficas e comportamentais (ANTUNES, 2003). Isso pode indicar que os professores acabam incentivando mais os alunos que buscam modificar o corpo do que aqueles que estão nas academias por outros motivos, destacando-se a socialização, busca de bem-estar ou melhora de habilidades psicológicas.

Inegavelmente, a postura adequada dos profissionais de educação física que trabalham em academias é fundamental para que esse seja um espaço saudável e de qualidade de vida. Coelho Filho e Votre (2010) alertam para o fato de que cabe aos professores de educação física refletirem criticamente sobre a forma como querem atuar, cabendo a esses profissionais a responsabilidade de atuar de forma correta e zelosa, buscando aumentar o bem-estar dos alunos nas academias de ginástica. $\mathrm{O}$ psicólogo, então, pode atuar na busca dessa conscientização através de treinamentos com os professores.

O estudo de liderança com professores e treinadores em diversas áreas pode auxiliar nesses treinamentos. Para Brandão e Carchan (2010, p. 3), a definição de liderança engloba várias dimensões do comportamento do treinador, como, por exemplo, seu processo de tomada de decisão, tipo de frequência que fornece estímulo ao atleta, seu desempenho, as técnicas de motivação utilizada e a forma de relação que estabelece com os atletas. Weinberg e Gould (2001), ainda acrescentam o feedback da administração de equipe como dimensões da liderança no esporte e exercício. Desse modo, o professor ou treinador é uma figura fundamental para a 
manutenção do clima entre os alunos, que interpretam os comportamentos, as atitudes e o estilo de liderança do seu técnico. Essas percepções contribuem consideravelmente para a criação e manutenção do clima nos treinos e competições (GONÇALVES et al, 2010). Para Orlick (2009), portanto, os treinadores devem ter habilidades de liderança e de comunicação bem desenvolvidas e seus relacionamentos devem ser baseados na confiança e no respeito (p. 283).

Chelladurai e Carron (1978), por sua vez, consideram o treinador um líder de uma organização particular, sendo os atletas os membros dessa organização. Assim, a maioria dos técnicos assume um determinado estilo de liderança que pode influenciar no desempenho das equipes e dos atletas que são comandados por ele. Assim, os professores têm um papel fundamental na manutenção dos alunos na academia e na diminuição da rotatividade (COELHO FILHO; VOTRE, 2010). Eles podem tentar trabalhar de forma individualizada, auxiliando a traçar metas individuais mais específicas para cada aluno, atentando para as pequenas mudanças. Ademais, podem dar mais feedbacks em relação ao treinamento, trabalhando com reforços individuais importantes para cada aluno. Quanto à academia, pode contribuir incentivando um programa de reforços, distribuindo recompensas por frequência e assiduidade nas atividades, entre outras ações que podem ajudar os alunos a alcançarem suas metas, o que servirá como reforçadores para a manutenção do comportamento de permanecerem ali.

Conforme Weinberg e Gould (2001) e Peres (2007), o fator ambiental é apresentado, pela literatura, como um forte influenciador na participação das pessoas em programas de atividade física, além de ter sido apontado pelos alunos como um fator de influência na permanência do aluno na academia. Nesse sentido, é importante entender como as pessoas se sentem no ambiente em que estão fazendo atividade física, daí a necessidade de se realizar uma pesquisa de clima com os alunos e com os professores, passo primordial que traz informações importantes, muitas vezes despercebidas pelos professores e pela administração das academias. Outrossim, a pesquisa pode contribuir para uma ação contextualizada do psicólogo do esporte em um campo ainda não explorado, além de permitir informações necessárias para formação de treinamentos com professores.

A avaliação do ambiente institucional é, pois, um método bastante utilizado pelo psicólogo, de forma geral, em outros contextos de atuação, dada a formação generalista desse profissional. Portanto, essa foi a primeira atuação a ser relatada nesta experiência de estágio. A avaliação com alunos e professores possibilitou a criação de treinamentos e a contextualização da atuação do psicólogo do esporte na academia, a qual será relatada a seguir.

O estágio na academia, inicialmente, foi organizado em uma única academia de ginástica, sob a supervisão de uma professora em Psicologia social, com uma carga horária diária de quatro horas. Primeiro houve o investimento no conhecimento do funcionamento da academia, por meio de entrevista com os alunos e professores; na construção do vínculo com a equipe de trabalho, que incluía a recepção, os professores, fisioterapeutas e nutricionistas; bem como no reconhecimento do território e das ações de trabalho em que a equipe atuava. A estagiária era supervisionada 
quinzenalmente pela professora de Psicologia, na universidade, levando as informações coletadas e refletindo sobre formas de atuar nesse ambiente.

\section{MÉTODO}

\section{Participantes}

Participaram dessa experiência os professores e alunos da academia selecionada. Com os professores foram ministrados treinamentos, a partir das informações coletadas por meio de um questionário direcionado aos alunos.

Esse questionário foi aplicado com 52 alunos, dentre os quais 35 eram mulheres e 17 eram homens. A idade média das mulheres era de 35,6 anos $(\mathrm{dp}=12,11)$ e dos homens era de 38,7 anos $(d p=16,25)$.

\section{Questões éticas}

Por se tratar de um estágio curricular, regido por um termo de convênio entre a universidade e o campo de estágio, não houve encaminhamento à Comissão de Ética na Pesquisa com Seres Humanos, visto que o artigo $6^{\circ}$ da Resolução no 016/2000 considera que "o psicólogo pesquisador poderá estar desobrigado do consentimento informado nas situações em que: I. envolvem observações naturalísticas em ambientes públicos". Dessa forma, a aplicação do questionário com os alunos serviu exclusivamente como forma de reconhecer o funcionamento daquele ambiente, bem como para formalizar as ações de estágio.

Os resultados da aplicação do questionário com os alunos são aqui divulgados com intuito de demonstrar uma forma de acessar as singularidades da academia onde ocorreu o estágio, estando sua aplicação inserida no item IV do mesmo artigo, da mesma resolução, que diz que o consentimento pode ser desobrigado caso "haja outras situações similares em que não há risco de violar a privacidade dos indivíduos envolvidos nem de causar a eles ou aos grupos e comunidades aos quais pertencem, qualquer tipo de constrangimento".

\section{Procedimentos}

O presente estudo se estabeleceu na efetivação de uma experiência de estágio curricular supervisionado, na área de Psicologia, em uma academia de ginástica. As supervisões foram realizadas quinzenalmente, por um professor com título de doutor, vinculado formalmente à Universidade Federal do Ceará. Dentre as ações iniciais, foi planejada e efetivada a aplicação de um questionário com os alunos da academia, com o objetivo de conhecer melhor como eles se relacionavam com esse ambiente. Os alunos foram abordados enquanto faziam uma atividade ergométrica, como bicicleta ou esteira, ou durante o alongamento final. Durante a avaliação, a estagiária preenchia o questionário, mas não identificava os alunos.

As ações do estágio foram planejadas a partir das informações obtidas através das respostas dos alunos a esse questionário, as quais ajudaram a pensar o conceito de qualidade de vida. Tais informações ainda auxiliaram na obtenção de dados relevantes para o recrutamento e seleção de novos funcionários e estagiários com o perfil identificado pelos alunos, bem como na 
avaliação de desempenho e no treinamento de professores e funcionários, direcionado às demandas de atendimento dos usuários.

\section{Materiais}

O questionário aplicado com os alunos foi criado pela estagiária e tinha como objetivo obter um perfil dos usuários, investigando como esses alunos avaliavam o ambiente físico da academia, como eles consideravam o atendimento dos professores e quais os fatores que contribuíam para que se mantivessem na prática de atividade física, incluindo ainda possíveis fatores que poderiam fazer com que desistissem. Os itens foram elaborados com base nos dados trazidos por Weinberg e Gould (2001), que apontam algumas razões para as pessoas se exercitarem e não se exercitarem. Sendo assim, os alunos respondiam questões como:

Você já frequentou outra academia? Por que saiu?

Por que você escolheu essa academia?

Há quanto tempo você está nessa academia? ( ) menos de 1 mês ( ) meses ( ) 1 ano

( ) 1 ano e meio ( ) 2 anos.

Os alunos também responderam questões fechadas com itens a serem escolhidos, por exemplo:

Qual é o seu objetivo na academia?

( ) hipertrofia (aumentar músculos)

( ) redução do percentual de gordura

( ) melhora do condicionamento físico

( ) estética corporal

( ) aliviar estresse/tensão

( ) outros"
( ) socialização (conhecer pessoas)

( ) melhoria da qualidade de vida

( ) diversão

( ) reabilitação

( ) performance esportiva 


\section{Análise Qualitativa}

O presente estudo se propôs a realizar uma avaliação qualitativa e utilizou de estatística descritiva dos resultados obtidos por meio de questionário. A análise selecionada baseou-se na descrição sistemática do que foi observado na pesquisa inicial com os alunos. Posto isso, os resultados estão apresentados em conjunto com a discussão sobre a utilização destas informações, em caráter aplicado.

\section{APRESENTAÇÃO E DISCUSSÃO DOS RESULTADOS}

Por meio desta investigação, foi verificado que a maioria dos alunos entrevistados estava treinando na academia há menos de um ano. Esse pouco tempo justifica-se porque, na época de realização do estágio, a academia tinha se estabelecido há menos de dois anos e estava se consolidando na cidade com uma nova proposta de um trabalho personalizado, que incluía a avaliação de um fisioterapeuta e orientações de uma nutricionista.

Quando perguntados sobre quais os objetivos de estarem praticando atividade física, cerca de $57,69 \%$ dos alunos tinham como objetivo diminuir o percentual de gordura, seguido pela necessidade de melhoria da qualidade de vida $48,07 \%$ e melhora do condicionamento físico $(38,46 \%)$.

Em relação aos motivos que o fizeram escolher aquela academia, a maioria $(26,92 \%)$ apontou que a proximidade de casa ou do trabalho foi a principal razão da escolha. O segundo motivo mais apontado foi a indicação de um amigo ou parente $(19,23 \%)$. Quando perguntados a respeito de quais os motivos que os fariam abandonar a academia, a maioria dos alunos apontou a distância de casa ou do trabalho, seguidos de pouco acompanhamento dos professores e da diminuição da motivação.

Foi verificado que a atenção dispensada pela equipe de professores e funcionários aos alunos é um importante motivo para mantê-los na academia, sendo essencial também para que se sintam bem e confortáveis naquele ambiente. Esse resultado corrobora com a literatura que aponta que o reforço social, a satisfação pessoal e as características dos instrutores e professores são fundamentais para a manutenção na prática regular de atividade física (PERES, 2007).

A partir das informações coletadas com os alunos, as ações da Psicologia dentro da academia foram direcionadas principalmente para trabalhos com treinamento e conscientização dos professores e outros funcionários, a fim de estimular a sensibilização acerca dessas informações e, assim, melhorar o atendimento aos clientes. A intervenção foi planejada durante as sessões de supervisão. Algumas ações foram efetivamente realizadas pela administração, após as pesquisas com os alunos, tais como mudanças nos boxes do banheiro, conserto de fechaduras, colocação de quadro de fotos das posições de alongamento, colocação dos nomes de todos os aparelhos, diminuição da poluição sonora e visual, diminuição do uso de copos descartáveis e incentivo do uso de garrafinhas.

Quanto às ações do psicólogo do esporte na academia, podem ser sintetizadas em cinco vertentes:

A) Programa de treinamento contínuo: com as informações obtidas por meio do 
questionário, pôde-se conhecer melhor o público da academia e programar ações direcionadas ao treinamento dos funcionários, no que diz respeito ao atendimento ao público e de marketing pessoal dos professores. O objetivo foi fazer com que eles valorizassem seus serviços, buscassem a melhoria contínua para atender os clientes e fossem reconhecidos por isso, motivando os alunos, dando mais atenção. Tal atitude, aliada à modificação dos movimentos errados, oferecendo ajuda mesmo quando não é solicitado, demonstra preocupação com o bem-estar físico dos alunos.

B) Programas sociais na academia: com o objetivo de potencializar o ambiente da academia como um local de socialização e interação entre as pessoas, transformando a prática de atividade física em um momento de diversão e descontração, foram planejadas ações de acordo com a identificação de demandas de interações sociais, verdadeiras contribuintes para permanência e comprometimento dos alunos com as atividades da academia. Nessa perspectiva, foram organizadas festas em datas comemorativas, programas de aniversariantes do mês, corridas sociais, trilhas e passeios externos.

C) Estabelecimento de metas e acolhimento psicológico: por meio da aplicação do questionário e o contato com os professores, foi identificada uma demanda de atendimento psicológico para auxiliar os alunos na motivação e no comprometimento com a rotina de exercícios permanentes. Assim, foi planejada uma avaliação psicológica, com objetivo de estabelecer metas em relação à rotina de exercícios e possibilitar um acolhimento psicológico dos alunos (KOVÁCS; KOBAYASHI; SANTOS; AVANCINI, 2001). A proposta da avaliação psicológica consistia em acolher o aluno em suas questões pessoais; construir um espaço de reflexão sobre os problemas vivenciados, na busca de uma melhor qualidade de vida; e estabelecer metas e buscar potencializar as ações para efetivar a prática de atividade física regular. Ao acolher os alunos, objetivava-se realizar uma escuta atenta à problemática trazida por eles, a fim de adequar as ações do nutricionista e do educador físico ao perfil do usuário da academia, de contribuir com as outras avaliações já realizadas como a avaliação física, postural e nutricional. Esse acolhimento psicológico pode ser um diferencial em uma academia, pois, ao ouvir o indivíduo para saber das suas expectativas, desejos/motivações e resistências, escolha é possível escolher a atividade esportiva mais adequada às necessidades dos alunos, contribuindo para diminuir as desistências constantes nesse ambiente esportivo. Esse acolhimento psicológico possibilita o encaminhamento do aluno à psicoterapia ou atendimento psiquiátrico, quando necessário, e, dependendo das características e da gravidade da situação, serve como forma de prevenção em saúde mental, importante ação do psicólogo. Além disso, por se tratar de uma ação conjunta com as outras especialidades da academia, pode-se estimular a concretização de um trabalho multidisciplinar.

D) Recrutamento e seleção de pessoal: a contratação de estagiários e funcionários passou a ser mais rigorosa. Foi construído um roteiro de entrevista e criado um pequeno exame teórico-prático para avaliar o nível teórico dos estagiários, bem como um período de experiência prática de uma semana antes da contratação oficial. Com 45 dias após a entrada do estagiário, foi realizada uma avaliação de desempenho com os professores responsáveis sendo passadas as informações necessárias para a melhoria do serviço. Também foram realizadas observações sistemáticas do trabalho dos estagiários, recepcionistas e professores contratados. Essa ação foi positiva, na medida em que trouxe mais seriedade e exigência na contratação de novos funcionários, que recebiam informações prévias sobre o funcionamento da academia. 
E) Pesquisas contínuas com os alunos: as pesquisas realizadas na academia foram extremamente importantes, pois os alunos tiveram a oportunidade de falar como consideravam o serviço da academia. Por conseguinte, a administração teve possibilidade de fazer as modificações que realmente eram importantes para os alunos.

\section{CONSIDERAÇÕES FINAIS}

O trabalho psicológico, dentro do ambiente das academias, considerando as singularidades deste espaço, é possível quando se tem apoio de todos os envolvidos. Destarte, antes de qualquer intervenção, é necessário que o psicólogo conheça bem o ambiente no qual ele está se inserindo. A aplicação do questionário com os alunos mostrou ser uma boa forma de identificação da demanda que pode ser alvo de intervenções, permitindo também o planejamento de estratégias direcionadas à prevenção e manutenção do bem-estar psicológico dos funcionários e alunos da academia, bem como uma forma de contato com a diretoria.

O investimento dos professores na formação e na melhoria do atendimento parece ser fundamental. Pensando nisso, foi identificada que a experiência aqui circunscrita oferece indícios de que o trabalho do psicólogo dentro de uma academia de ginástica deve ser realizado com toda a equipe de profissionais (professores, funcionários e estagiários) e também com os alunos da academia, tendo como objetivo principal contribuir para que o ambiente da academia se torne cada vez mais acolhedor e completo, compreendendo todas as dimensões humanas (física, nutricional, postural e psicológica), o que parece auxiliar na melhoria do bem-estar físico e emocional de seus clientes.

Outro ponto importante que pode ser alvo de avaliação e intervenção são os aspectos psicossociais. Como em qualquer espaço, o psicólogo deve estar atento às demandas sociais que surgem nesse ambiente, tentando proporcionar a busca do bem-estar físico, cuidado com a saúde mental e a qualidade de vida dos indivíduos com os quais se trabalha.

Conclui-se, pois, que a pesquisa e a atuação em Psicologia do esporte exigem um treinamento do olhar para os relacionamentos sociais, para o contexto, para a resolução de problemas, para as emoções e cognições, para a busca de saúde, de qualidade de vida e socialização. Com esse objetivo, o fazer da Psicologia sempre deve estar voltado ao coletivo, pois somos seres sociais e o olhar do psicólogo deve sempre abranger a relação do homem com o meio que o circunda, não de maneira dicotômica (homem $x$ ambiente), mas de forma dialética, onde um influencia o outro, onde o agente modifica e é, ao mesmo tempo, modificado por esse meio.

Além disso, o trabalho do psicólogo do esporte no ambiente das academias deve contribuir para que a prática de atividade física se torne, cada vez mais, um momento de diversão e descontração da vida cotidiana do indivíduo. Essa transformação contribui para a permanência, comprometimento e manutenção do indivíduo em um programa regular de atividade física, pois a satisfação e o bem-estar são apontados como fatores determinantes para a participação em programas de exercícios físicos.

Percebe-se, então, que as atuações realizadas na experiência aqui relatada não fugiram das atuações habituais do 
psicólogo. O trabalho desse profissional dentro de uma academia tem, portanto, uma importância inovadora, em se tratando de um ambiente pouco ocupado por aqueles que atuam nessa área. Se essa inserção for cada vez mais realizada talvez seja possível contribuir para que o ambiente das academias seja ainda mais acolhedor e mais humanizado, o que poderia trazer mais satisfação e uma maior adesão dos alunos.

Nessa perspectiva, o psicólogo do esporte se estabelece como facilitador que auxilia os professores de educação física a terem um olhar mais humano e individual das pessoas que procuram atividades dentro das academias. Logo, esses profissionais precisam ter maior consciência sobre motivações, exageros e distorções que, porventura, possam existir na prática de atividade física. Além disso, é importante para a formação dos profissionais de Psicologia que atuem em áreas ainda em crescimento e desenvolvimento, que busquem enfrentar os desafios de redimensionamento de suas práticas, refletindo em ações contextualizadas e fundamentadas teórica e metodologicamente.

\section{REFERÊNCIAS}

ANTUNES, A. C. Perfil profissional de instrutores de academias de ginástica e musculação. EFDeportes.com, Revista Digital, Buenos Aires, a. 9, n. 60, maio, 2003.

BAUDRILLARD, J. A sociedade de consumo.

Lisboa: Edições 70, 1995.

BRANDÃO, M. R. F.; CARCHAN, D. Comportamento preferido de liderança e sua influência no desempenho dos atletas.

Motricidade, v. 6, n. 1, p. 53-69, 2010.

CARVALHO, M. T. M., SAMPAIO, J. R. A formação do psicólogo e as áreas emergentes. Psicologia, ciência e profissão, 1997, 17, (1), 14-19.

COELHO FILHO, C. A. A.; VOTRE, S. J. Imagens da prática profissional em academias de ginástica na cidade do Rio de Janeiro. Revista Brasileira de Ciência do Esporte (Campinas), v. 31, n. 3, p. 95-110, 2010.

CHELlaDURAI, P.; CARRON, A. V.

Psychology factors and athletic success: an analysis

of coach-athlete interpersonal behavior.

Can. J. Appl. Physiol., Champaign, v. 3, n. 1, p. 43-50, 1978.

DEBORD, G. A sociedade do espetáculo: comentários sobre a sociedade do espetáculo. Tradução de Estale dos Santos Abreu. Rio de Janeiro: Contraponto, 1994.

EPIPHANIO, E. H. Psicologia do esporte: apropriando a desapropriação. Psicologia ciência e profissão, v.19, n. 3, p. 70-73, 1999.

FLEGAL, K. M.; CARROLL, M. D.; OGDEN, C. L.; CURTIN, L. R. Prevalence and Trends in Obesity Among US Adults, 1999-2008. JAMA - The Journal of the American Medical Association, v. 303, n. 3, p. 235-241, 2010.

GONÇALVES, C. E.; COELHO e SILVA, M. J.; CRUZ, J.; FIGUEIREDO, A. Efeito da experiência do treinador sobre o ambiente motivacional e pedagógico no treino de jovens. Revista Brasileira de Educação Física e Esporte, v. 24, n. 1, p. 15-26, 2010.

HANSEN, R.; VAZ, A. F. Treino, culto e embelezamento do corpo: um estudo em academias de ginástica e musculação. Revista Brasileira de Ciências do Esporte, Campinas, v. 26, n. 1, p. 135-152, 2004. 
KOVÁCS, M. J., KOBAYASHI, C., SANTOS, A. B. B., AVANCINI, D. C. F. Implantação de um serviço de plantão psicológico numa unidade de cuidados paliativos. Boletim de Psicologia, 51(114), 1-22, 2001.

LISBOA, F. S.; BARBOSA, A. J. G. Formação em Psicologia no Brasil: Um Perfil dos Cursos de Graduação. Psicologia Ciência e Profissão, v. 29, n. 4, p. 718737, 2009.

MACHADO, P. X.; CASSEPP-BORGES, V.; DELL'AGLIO, D. D.; KOLLER, S. H. O impacto de um projeto de educação pelo esporte no desenvolvimento infantil. Revista Semestral da Associação Brasileira de Psicologia Escolar e Educacional (ABRAPEE), v. 11, n. 1, p. 51-62, 2007.

MARTIN, G. L. Consultoria em Psicologia do esporte - orientações práticas em análise do comportamento. Traduzido por: Noreen Campbel de Aguirre. Campinas: Instituto de Análise do Comportamento, 2001.

MONTEIRO. A psicologia do esporte e academias de ginástica. Em Cozac, J. R. L. Psicologia do esporte, clinica, alta performance e atividade física. São Paulo: Annablume, 2004.

ORLICK, T. Em busca da excelência: como vencer no esporte e na vida. Porto Alegre: Artmed, 2009.

PERES, J. H. S. Fatores que influenciam na adesão e aderência a um programa de exercícios físicos supervisionados. Monografia do curso de Educação Física, Universidade Estadual Paulista UNESP, Bauru, São Paulo, 2007.

RUBIO, K. Da Psicologia do Esporte que temos à Psicologia do Esporte que queremos. Revista Brasileira de Psicologia do Esporte, 1(1), 01-13, 2007.

RUBIO, K. Origens e evolução da psicologia do esporte no Brasil. Revista Bibliográfica de geografía y ciencias sociales, v. 7, n. 373, 2002.

SEVERIANO, M. F. V.; REGO, M. O.; MONTEFUSCO, E. V. R. O corpo idealizado de consumo: paradoxos da hipermodernidade. Revista Mal-estar e subjetividade (Fortaleza), n. 5, v. 1, p. 137-165, 2010.

SILVA, A. M. B. FOCH, G. F. L., GUIMARÃES, C. A. ENUMO, S. R. F. Instrumentos aplicados em estudos brasileiros em psicologia do esporte. Estudos Interdisciplinares em Psicologia, Londrina, v. 5, n. 2, p. 7795, dez. 2014.

SPECTOR, P. E. Psicologia nas organizações. São Paulo: Saraiva, 2010.

TAHARA, A. K.; SCHWARTZ, G. M.; SILVA, K. A. Aderência e manutenção da prática de exercícios em academias. Revista Brasileira Ciência Movimento (Brasília), n. 11, v. 4, p. 7-12, 2003.

THEODORO, H.; RICALDE, S. R.; AMARO, F. S. Avaliação nutricional e autopercepção corporal de praticantes de musculação em academias de Caxias do Sul - RS. Revista Brasileira de Medina do Esporte, v. 15, n. 4, p. 291-294, 2009.

TOLEDO, E.; PIRES, F. R. Sorria! Marketing e consumo dos programas de ginástica de academia. Revista Brasileira de Ciências do Esporte, Campinas, v. 29, n. 3, p. 41-56, 2008.

WEINBERG, R. S.; GOULD, D. Fundamentos da Psicologia do Esporte e do exercício. Porto Alegre: Artmed, 2001. 


\section{REFLECTIONS ON SPORT PSYCHOLOGIST WORKING IN FITNESS CENTERS}

\section{ABSTRACT}

This study sought to develop a reflection on the sport psychologist practice within a health club, from the report of internship experience in psychology. We reflect on the role of this professional in that area, seeking to build tune actions with the sports psychology field. The work encompassed interventions with students and teachers. At the end, stage experience pointed to the possibility of sport psychologist's performance in the gyms, pointing to health promotion and support team work, thus contributing to the development of actions in the field of sport psychology.

Keywords: Psychology; Fitness Centers; Motor Activity

\section{REFLEXIONES SOBRE PSICÓLOGO DEL DEPORTE DE TRABAJO EN CENTROS DE ACONDICIONAMIENTO}

\section{RESUMEN}

Este estudio trata de desarrollar una reflexión sobre la práctica psicólogo del deporte en un club de salud, a partir del informe de la experiencia de prácticas en psicología. Reflexionamos sobre el papel de este profesional en esa área, buscando construir acciones sintonía con el campo de la psicología del deporte. El trabajo abarcó intervenciones con alumnos y profesores. Al final, la experiencia etapa apuntó a la posibilidad de que el rendimiento deportivo del psicólogo en los gimnasios, que apunta a promover la salud y el trabajo en equipo de apoyo, contribuyendo así al desarrollo de acciones en el campo de la psicología del deporte.

Palabras clave: Psicología; Centros de Acondicionamiento; Actividad Motora

Recebido em: junho/2015

Aprovado em: setembro/2015 